\title{
IMPROVING EXTREME RAINFALL EVENT PREDICTION USING MICROWAVE SATELLITE DATA ASSIMILATION
}

\author{
Felix MUTUA ${ }^{1}$, Mohamed RASMY ${ }^{2}$, and Toshio KOIKE ${ }^{3}$ \\ ${ }^{1}$ Student Member of JSCE, Ph. D. Student, Dept. of Civil Eng., University of Tokyo (Bunkyo-ku, Tokyo 113-8656, \\ Japan) \\ ${ }^{2}$ Member of JSCE, Dr. Eng., Researcher, Dept. of Civil Eng., University of Tokyo (Bunkyo-ku, Tokyo 113-8656, \\ Japan) \\ ${ }^{3}$ Member of JSCE, Dr. Eng., Professor, Dept. of Civil Eng., University of Tokyo (Bunkyo-ku, Tokyo 113-8656, Japan)
}

\begin{abstract}
Microwave Satellite data has become very useful in weather prediction through data assimilation for improving Numerical Weather Prediction (NWP) initial conditions. By assimilating 23GHZ (sensitive to water vapor) and $89 \mathrm{GHZ}$ (sensitive to cloud water) brightness temperature, the predictability of an extreme rain weather event over Lake Victoria, East Africa is investigated. The assimilation of AMSR-E brightness temperature (TB) through a Cloud Microphysics Data Assimilation (CMDAS) into a NWP considerably improves the spatial distribution of this event. Assimilating cloud water, water mixing ratio and other ice cloud components inserts clouds, triggers weak surface convergence and consequent convection. The spatial distribution of the simulated event is comparable to observed satellite rainfall. Through assimilation, smaller events missed by the downscaling experiment are introduced into the model state and this leads to a better forecast. The integrated cloud condensate follows a similar pattern to observed cloud top temperature with the probability of detection improving as well. However, even though the system is able to reproduce a reasonable distribution of this event, there still remains overestimation especially over the regions of maximum precipitation.
\end{abstract}

Key Words: Extreme event, assimilation, weather forecasting, brightness temperature, Lake Victoria

\section{INTRODUCTION}

Extreme rainfall events have a large and sometimes devastating effect on communities especially those living in developing countries. Floods, infrastructure damage, loss of lives and destruction crops are some of the adverse effects associated with extreme rainfall. To mitigate, prevent, or even anticipate these natural disasters, it's important to have a reliable weather prediction system in order to provide timely and life / property saving early warnings. Numerical weather prediction models, regional and global weather forecasting systems are some of the integrated systems used to provide timely early warning systems. In Africa as well as other developing regions, the utilization of these tools and knowledge are still limited. Faced with a changing climate coupled with recurrent floods, there has been continuous loss of property and lives.

The primary ingredient to these disasters especially floods is rainfall which over the years, despite advancement in modeling, computing power and use of new data and technologies, has proven difficult to predict. Numerical weather prediction
(NWP) models using global forecasts as initial and boundary conditions have been used to provide short to midterm forecasts in many parts of the world. The prediction of landfall for cyclones, hurricanes, and typhoons has benefited greatly from the advanced regional and global forecast models.

In addition, satellite data has provided immense improvement in prediction of extreme events. Through data assimilation both in the visible and microwave regions of the electromagnetic spectrum, the prediction of frequency and intensity of rainfall events has seen great improvement. Assimilation of weather variable retrievals e.g. ${ }^{1,2), 3)}$ from satellite data as well as the raw radiances e.g. ${ }^{4), 55,6), 7), 8)}$ has produced improvements in many applications.

Despite this, quantitative precipitation forecast (QPF) remains as one of the most challenging tasks of weather prediction ${ }^{9), 10), 11)}$ which has not yet been satisfactorily resolved in the NWP models. This study attempts to improve quantitative rainfall prediction of an extreme event in the Lake Victoria Basin, East Africa. By using a Coupled Land Data Assimilation system (CALDAS) ${ }^{12)}$ Advanced Regional Prediction (ARPS) mesoscale model ${ }^{13)}$ and Advanced Microwave Scanning Radiometer 
(AMSR-E) brightness temperature data(TB); assimilation was done for $4^{\text {th }}$ April 2004 at 23:10 and a 6 hour forecast run initiated after that.

\section{STUDY AREA}

The Lake Victoria Basin (LVB) has a size of $194,000 \mathrm{~km}^{2}$, with the Lake surface covering an area of about $68,800 \mathrm{~km}^{2}$, (Fig. 1). The Basin area is shared between riparian states of Tanzania (44\%), Kenya (22\%), Uganda (16\%), Burundi (7\%) and Rwanda $(11 \%)$. The Lake Victoria Basin holds world leading status for freshwater Lake size, elaboration of vertebrate species diversity, species extinctions, exotic species invasions, and freshwater fishery production. The Lake is high in elevation, mostly enclosed by highlands and mountain ranges.

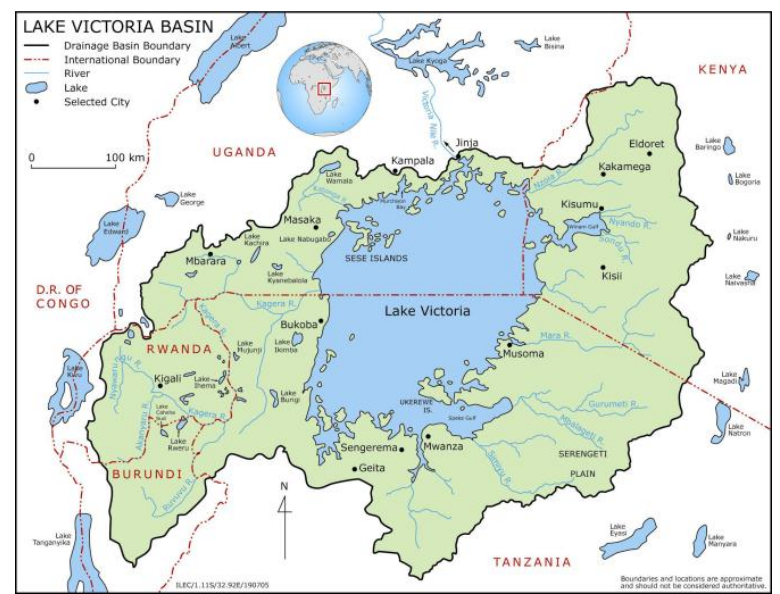

Fig. 1 Lake Victoria basin, East Africa: adapted from Strategic Action Plan (SAP) for the Lake Victoria Basin

Rainfall in this region is mainly influenced by the migration of the Inter tropical Convergence zone (ITCZ) and exhibits a bi-modal pattern with peaks in March-April-May (MAM) and October-November-December (OND), known as long rains and short rains respectively ${ }^{14), 15), 16)}$. The mean annual rainfall ranges from $800 \mathrm{~mm}$ in the lowlands to about $1600 \mathrm{~mm}$ in the highlands.

Other regional and synoptic scale phenomena like the Indian Ocean Dipole have been shown to influence the East African climate as a whole ${ }^{17)}$. Floods on the lower Kano plains occur frequently and this has affected the livelihoods of about 1.1 million people.

\section{METHODOLOGY}

\section{(1) Data and tools}

The Coupled Atmosphere Land Data Assimilation System (CALDAS) used in this study is an integrated system of a mesoscale storm model (ARPS), a Land data assimilation system (LDAS-A) and a cloud microphysics data assimilation system (CMDAS) ${ }^{18)}$. The LDAS-A was developed to improve the surface moisture heterogeneity through the assimilation of lower frequency satellite passive microwave observations such as those at 6.9 and $10.65 \mathrm{GHz}$.

\section{a) Cloud microphysics scheme}

The CMDAS component assimilates microwave satellite data at the $23 \mathrm{GHZ}$ (sensitive to water vapor) and $89 \mathrm{GHZ}$ (for cloud water). Brightness temperature from the AMSR-E sensor is used in the CALDAS system. AMSR-E is a twelve-channel, six-frequency, total power passive-microwave radiometer system. It measures brightness temperatures at $6.925,10.65,18.7,23.8$, 36.5 , and $89.0 \mathrm{GHz}$. The CMDAS algorithm includes Lin's ice cloud microphysics scheme, a radiative transfer model (RTM) in the microwave region, and an optimization method; the Shuffled Complex Evolution (SCE). The four-stream fast RTM developed by ${ }^{19)}$ is used to calculate the microwave TB from the model operator output.

\section{b) Mesoscale model}

The ARPS model is used as the mesoscale operator and the LDAS-A coupled with the revised simple biosphere model $(\mathrm{SiB} 2)^{20)}$ as the land surface operator. ARPS is a non-hydrostatic atmospheric prediction model and is appropriate for use on scales ranging from a few meters to hundreds of kilometers. It is based on compressible Navier-Stokes equations describing the atmospheric flow, and uses a generalized terrain-following coordinate system.

\section{c) Model data}

The National Center for Environmental Prediction (NCEP) Global Forecast System (GFS) final (FNL) gridded analysis dataset is used both for initial and boundary conditions. The Tropical Rainfall Measuring Mission (TRMM) 3-hourly rainfall dataset is used for validation partly due to lack of adequate observations in this region. Visual comparison and contingency based statistics were used to evaluate model performance.

\section{(2) Event selection}

Three factors were taken into consideration in selecting the extreme event to investigate. 1) AMSR-E coverage, being located at the equator the coverage is limited to once in a few days for full domain, 2) A recorded coincidence of rainfall covering at least a quarter of the basin with maxima over the lake or adjacent areas and 3) a day(s) with 
continuous mesoscale cloud system lasting for at least 6 hours. The Globally-merged, full-resolution $(\sim 4 \mathrm{~km})$ infrared (IR) dataset was used for this purpose. $4^{\text {th }}$ April, 2004 met these criteria and was selected for this study.

\section{(3) Model and domain setup}

A nested model set up was employed in this study with the outer domain (Grid1) of $30 \mathrm{~km}$, a second domain (Grid2) of $10 \mathrm{~km}$ and the finer domain (Grid3) of $5 \mathrm{~km}$. Assimilation was only done for Grid3. Fig. 2 shows the location and domain set up. The mesoscale model was configured with 1.5 TKE-based closure system, SiB2 land surface scheme, turbulent mixing, Lin ice microphysics scheme and cumulus parameterization for Grid 1 and Grid2.

The experiment was initiated at 06UTC for the outer domain (Grid1), 12UTC for Grid2 and 18UTC for the innermost domain (Grid3). Assimilation was done at 23:10UTC when data became available. AMSR-E TB at $23 \mathrm{GHZ}$ and $89 \mathrm{GHZ}$ frequencies were assimilated through a radiative transfer model and the shuffled evolution complex was used to minimize the cost function. To test the performance of CALDAS potential as a forecast tool, a forecast run was initiated after assimilation by using nesting with boundary conditions from Grid2.

NWP model performance was evaluated by comparing forecasted rainfall against TRMM and model predicted integrated cloud condensate pattern against observed cloud top temperature. In addition, probability of detection (POD) and false alarm ratio (FAR) statistics were computed based on contingency table results.

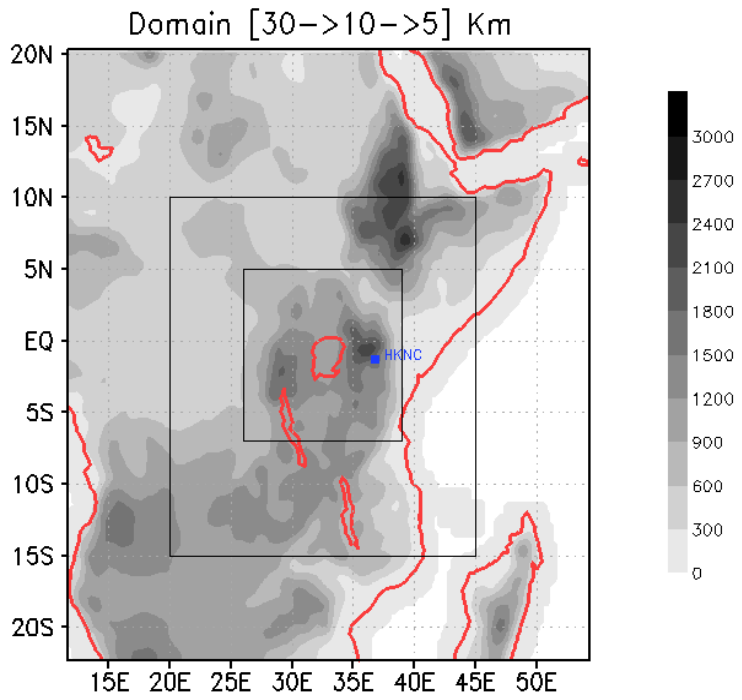

Fig. 2 Nested domain set up $(30 \mathrm{Km}>10 \mathrm{Km}>5 \mathrm{Km})$
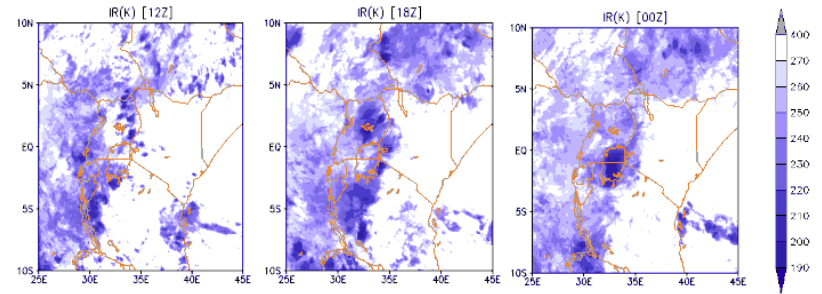

Fig. 3 Observed IR Cloud top Temperature (K) at 12UTC, 18UTC $4^{\text {th }}$ April and 00UTC $5^{\text {th }}$
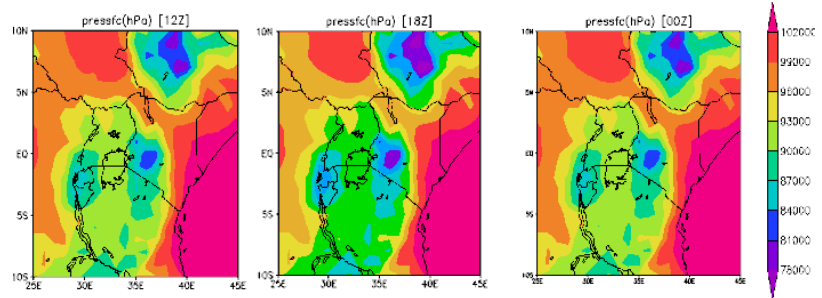

Fig. 4 Pressure at 12UTC, 18UTC $4^{\text {th }}$ April and 00UTC $5^{\text {th }}$

\section{(1) Synoptic conditions, $4^{\text {th }}$ April, 2004}

Fig. 3 shows the observed cloud top temperature from 21UTC $\left(4^{\text {th }}\right)$ to 00UTC ( $5^{\text {th }}$ April). A strong mesoscale convective system existed over the lake region. The accumulated daily rainfall for $4^{\text {th }}$ April at Kitale station $(35 \mathrm{E}, 1 \mathrm{~N})$ exceeded $85 \mathrm{~mm}$. This is above the 99.98 percentile $(71.70 \mathrm{~mm} /$ day $)$ for the period 1973-2004 and also the $26^{\text {th }}$ highest amount recorded at this station for the same period. This is the highest rainfall amount recorded at this station for 2004.

A system of low pressure associated with synoptic scale convection existed over the region for more than 6 hours (Fig. 4) with low pressures system over the Ethiopian highlands, the Nandi hills (East of Lake Victoria) and western sides of the Lake. This twin pressure system continued strengthening at about 18UTC. Also, a synoptic scale surface convergence (not shown) was present from about 12UTC and continued over the lake till about midday on $5^{\text {th }}$ April when the circulation developed into a predominantly south-easterly flow around the Ethiopian highlands.

\section{RESULTS AND DISCUSSIONS}

To investigate the effect of assimilation, two experiments were set up. The first experiment (ARPS) is just a downscaling run without assimilation while the assimilation case is $\boldsymbol{C A L D A S}$. Both experiments use same initial and boundary conditions. Immediately after assimilation, a forecast run was initiated with the improved state variables as initial conditions. 

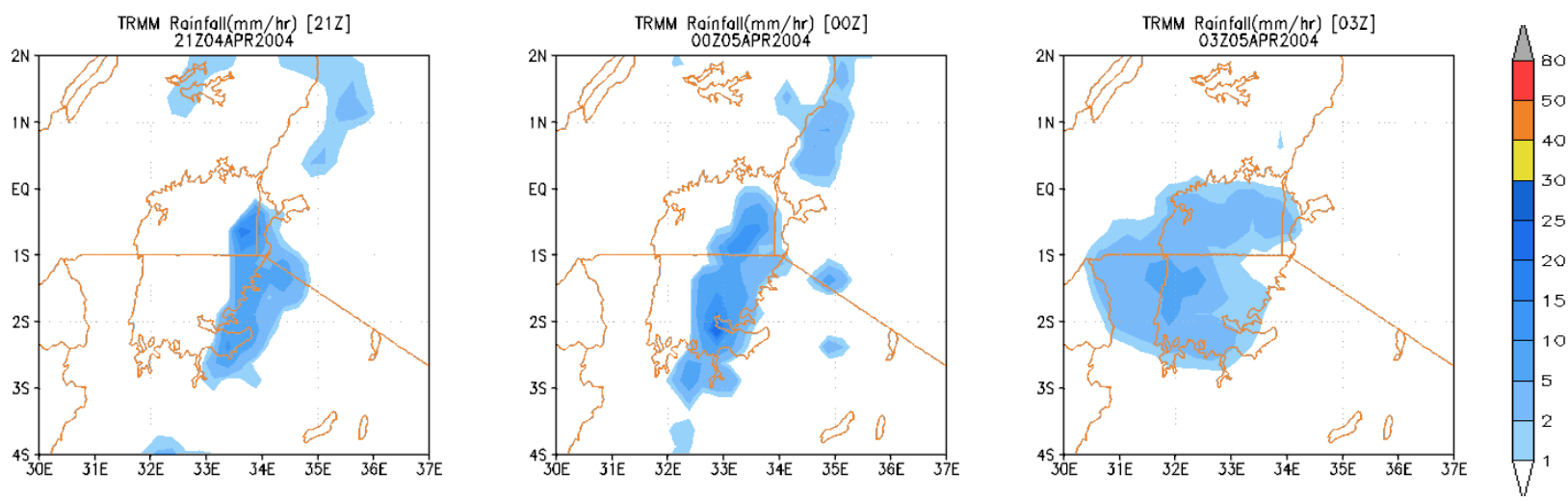

Fig. 5 Accumulated TRMM rainfall for $21 \mathrm{UTC}\left(4^{\text {th }}\right.$ April $)$, 00UTC $\left(5^{\text {th }}\right)$ and 03UTC respectively
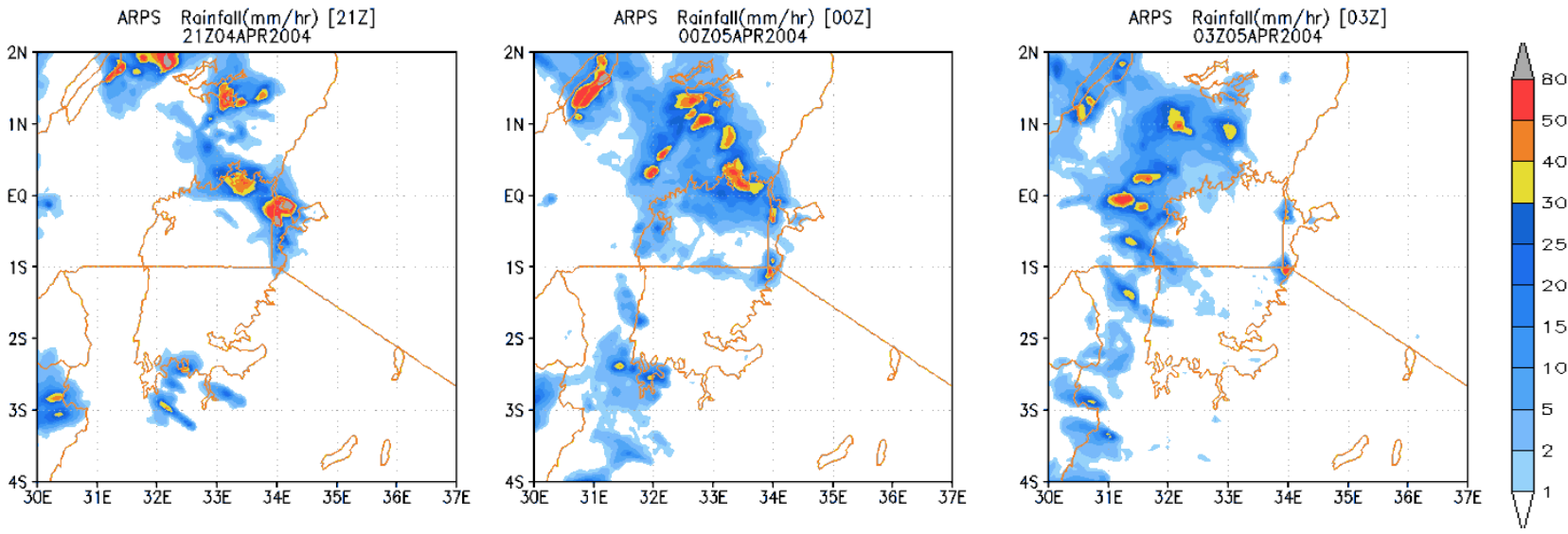

Fig. 6 Accumulated 3-hourly rainfall (ARPS) for 21UTC $\left(4^{\text {th }}\right.$ April), 00UTC $\left(5^{\text {th }}\right)$ and 03UTC respectively
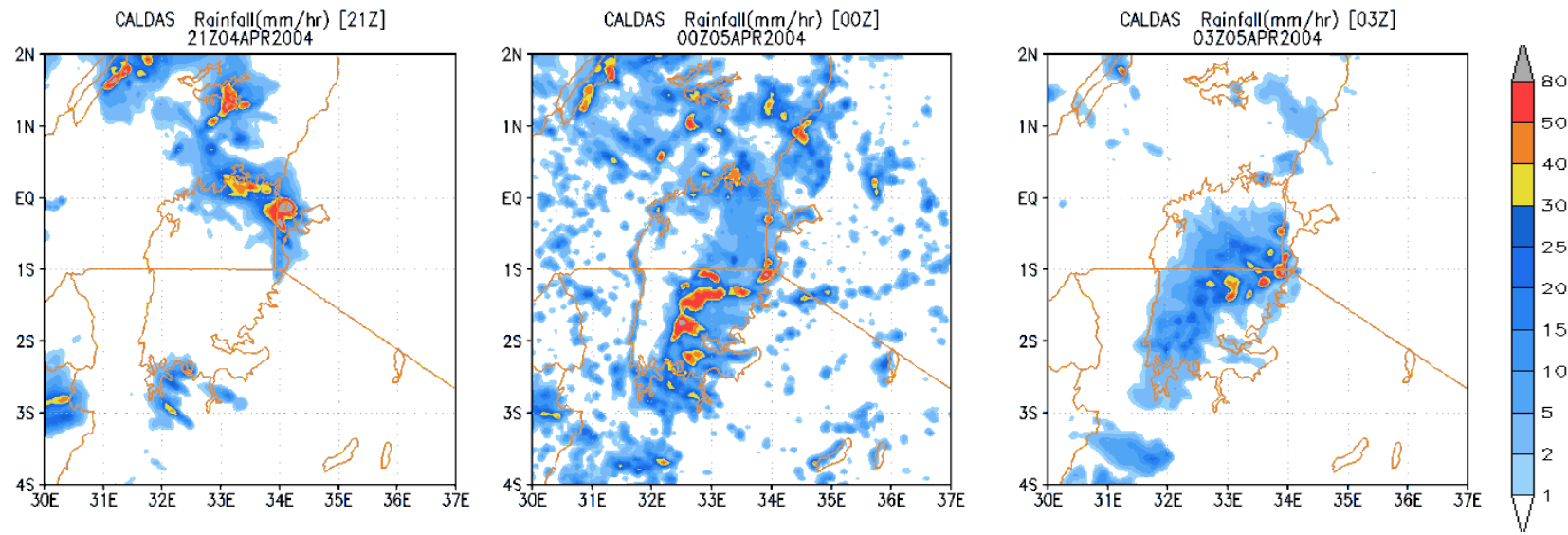

Fig. 7 Accumulated 3-hourly rainfall (CALDAS) for 21UTC $\left(4^{\text {th }}\right.$ April), 00UTC $\left(5^{\text {th }}\right)$ and 03UTC respectively
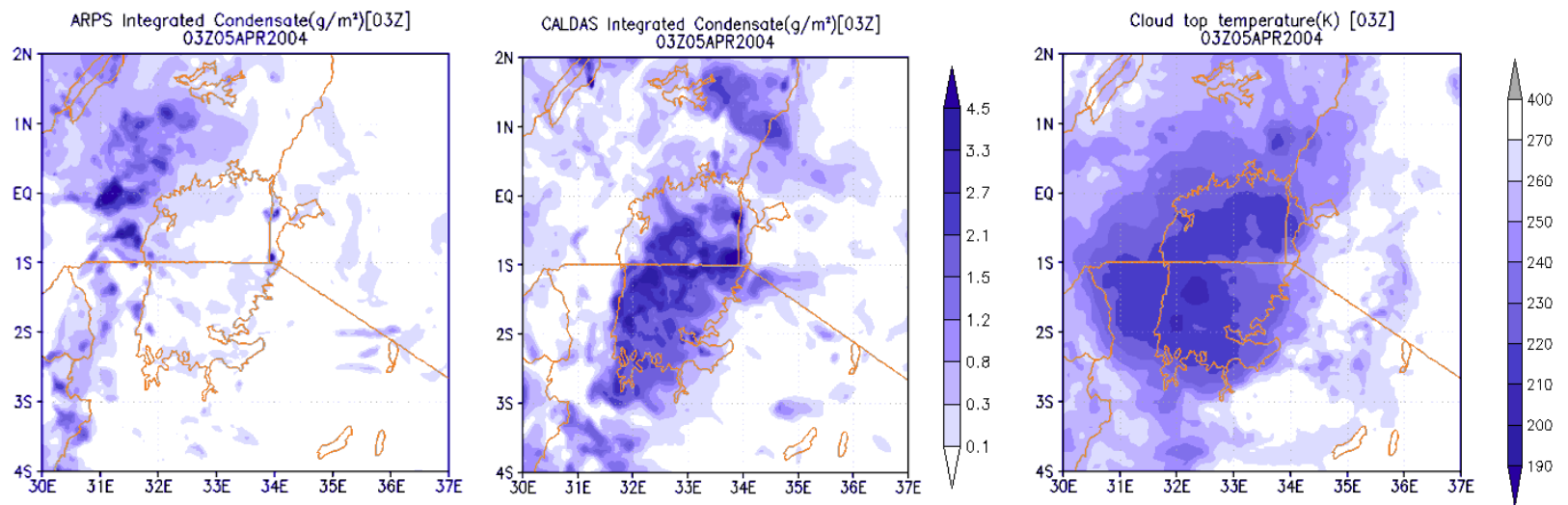

Fig. 8 Integrated cloud condensate for ARPS (left), CALDAS (center) and observed IR Clout top Temperature (K) (right) at 03UTC on $5^{\text {th }}$ April 2004 

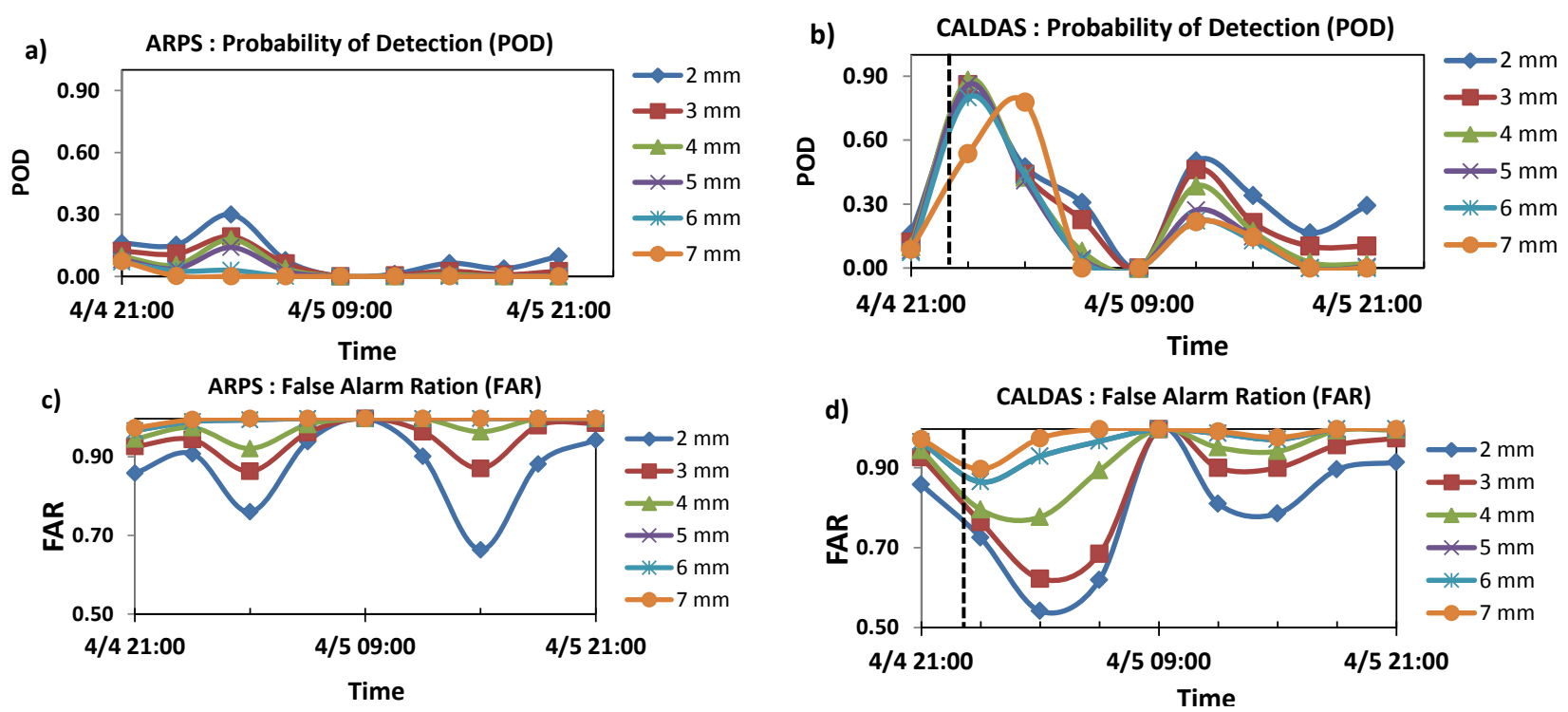

Fig. 9 Probability of detection (POD) (a, b) and false alarm ratio (FAR) (c, d) for ARPS and CALDAS respectively. The black line on b) and d) shows the assimilation time

\section{(1) Rainfall (without assimilation, ARPS)}

Fig. 6 shows the simulated 3-hour accumulated rainfall for the ARPS experiment. This downscaling experiment is able to reproduce this extreme event to some degree of accuracy. At 21UTC, the ARPS run simulate rainfall north of Lake Victoria as well as some weak pattern south. TRMM recorded rainfall over the lake at 00UTC $\left(5^{\text {th }}\right.$ April) and this event continued for about six hours. At 00UTC $\left(5^{\text {th }}\right)$ when TRMM records a lined up rainfall over the lake, the ARPS run is not able to produce this pattern well and is characterized by excess rainfall NW of the domain However, at 03UTC on $5^{\text {th }}$, the system is able to reproduce similar weak pattern but rather displaced west with overestimation further north-west of the domain. In addition, the semi-autonomous event at around $(35 \mathrm{E}, 1 \mathrm{~N})$ is absent in this run.

\section{(2) Rainfall (with assimilation, CALDAS)}

The CALDAS run (Fig. 7) produces improved results after the assimilation of AMSR-E data at 23:10 UTC on $4^{\text {th }}$ April. At 00UTC the lined up pattern similar to TRMM is reproduced and also the run was able to introduce the semi-autonomous event around $(35 \mathrm{E}, 1 \mathrm{~N})$. The regions of maxima in both TRMM and CALDAS match but CALDAS tends to overestimate. The model is able to sustain this event and at 03UTC, we see improved "over the lake rainfall" with the overestimation NW of the domain seen in the ARPS run removed. Similar to 00UTC, the regions of maxima in this run matches closely to TRMM but characterized by overestimation.

Fig.8 shows the integrated condensate for both runs as compared to observed IR (cloud top temperature) at 03UTC on $5^{\text {th }}$ April. This numerical experiment suggests that the introduction of ice, cloud water and snow water into the model by assimilation improves the model physics and the simulated integrated condensate follows observed cloud pattern well. Qualitatively, the spatial distribution of precipitation is improved compared to the non-assimilation case (ARPS). However, more sensitivity experiments are needed to validate this improvement.

We calculated the probability of detection (POD) and false alarm ratio (FAR) of rainfall for the two experiments using a contingency table. As shown in Fig.9, assimilation considerably improves POD even though the amounts predicted are not good enough. Three hours after assimilation, the POD jumps from 0.2 to about 0.7 for thresholds ranging from $2 \mathrm{~mm}$ to $7 \mathrm{~mm}$. This is a considerable improvement compared to ARPS $(\sim 0.2)$. Also, the likely of predicting wrongly (i.e. FAR) also decreases with assimilation (e.g. from 0.9 at $21 \mathrm{UTC}$ to about 0.5 at 03UTC).

Though some aspects of this prediction at specific times is presented well, the spatial correlation between the predicted and observed is rather weak (less than 0.3 ) with only prediction at 03UTC $5^{\text {th }}$ April 2004 reaching a coefficient of 0.29 (CALDAS). This shows that with respect to spatial prediction, the model performs poorly and this is independent of the time of integration.

\section{CONCLUSIONS}

We investigated the added value of assimilating AMSR-E brightness temperature in simulating QPF for an extreme event in the LVB. Two numerical experiments were set up for downscaling only, and downscaling with assimilation. By "inserting" cloud, ice and snow 
hydrometers based on the brightness temperature into the ARPS model state; we see a remarkable improvement in the simulation of this extreme event. There is considerable qualitative improvement of QPF by assimilation which also introduces a semi-autonomous event missed by the downscaling experiment.

However, there still remains a challenge on quantitative forecasts even though spatially the event is simulated well. More studies are encouraged to validate CALDAS and test the performance on other events. Further research into improvement of the quantitative aspect is encouraged.

ACKNOWLEDGMENT: The study is supported by grants from the Ministry of Education, Culture, Sports, Science and Technology of Japan, the GRENE Environmental Information Project, and the DIAS project 2011-2015. The authors would also like to appreciate JAXA for the provision of AMSR-E data.

\section{REFERENCES}

1) E. Andersson, J. Pailleux, J.-N. Thépaut, J. R. Eyre, A. P. McNally, G. A. Kelly, and P. Courtier, Use of cloud-cleared radiances in three/four-dimensional variational data assimilation, Quarterly Journal of the Royal Meteorological Society, vol. 120, no. 517, pp. 627-653, 1994.

2) R. H. Reichle, Bias reduction in short records of satellite soil moisture, Geophysical Research Letters, vol. 31, no. 19, p. L19501, Oct. 2004.

3) L. Phalippou, Variational retrieval of humidity profile, wind speed and cloud liquid-water path with the SSM/I: Potential for numerical weather prediction, Quarterly Journal of the Royal Meteorological Society, vol. 122, no. 530, pp. 327-355, 1996.

4) J. R. Eyre, G. A. Kelly, A. P. McNally, E. Andersson, and A. Persson, Assimilation of TOVS radiance information through one-dimensional variational analysis, Quarterly Journal of the Royal Meteorological Society, vol. 119, no. 514, pp. 1427-1463, 1993.

5) W. B. Rossow and L. C. Garder, Cloud Detection Using Satellite Measurements of Infrared and Visible Radiances for ISCCP, Journal of Climate, vol. 6, no. 12, pp. 23412369, 1993.

6) R. Saunders, M. Matricardi, and P. Brunel, An improved fast radiative transfer model for assimilation of satellite radiance observations, Quarterly Journal of the Royal Meteorological Society, vol. 125, no. 556, pp. 1407-1425, 1999.

7) D. P. Dee and S. Uppala, Variational bias correction of satellite radiance data in the ERA-Interim reanalysis, Quarterly Journal of the Royal Meteorological Society, vol. 135, no. 644, pp. 1830-1841, 2009.

8) J. A. Aravéquia, I. Szunyogh, E. J. Fertig, E. Kalnay, D. Kuhl, and E. J. Kostelich, Evaluation of a Strategy for the
Assimilation of Satellite Radiance Observations with the Local Ensemble Transform Kalman Filter, Monthly Weather Review, vol. 139, no. 6, pp. 1932-1951, 2011.

9) R. J. Kuligowski and A. P. Barros, Localized Precipitation Forecasts from a Numerical Weather Prediction Model Using Artificial Neural Networks, Weather and Forecasting, vol. 13, no. 4, pp. 1194-1204, 1998.

10) O. Bousquet, C. A. Lin, and I. Zawadzki, Analysis of scale dependence of quantitative precipitation forecast verification: A case-study over the Mackenzie River basin, Quarterly Journal of the Royal Meteorological Society, vol. 132, no. 620, pp. 2107-2125, 2006.

11) C. Lu, H. Yuan, E. I. Tollerud, and N. Wang, Scale-Dependent Uncertainties in Global QPFs and QPEs from NWP Model and Satellite Fields, Journal of Hydrometeorology, vol. 11, no. 1, pp. 139-155, 2010.

12) Rasmy, M., Koike, T., Kuria, D., Mirza, C. R., Li, X., and Yang, K. Development of the Coupled Atmosphere and Land Data Assimilation System (CALDAS) and Its Application Over the Tibetan Plateau. IEEE Transactions on Geoscience and Remote Sensing, 50(11), 4227-4242. 2012

13) M. Xue, K. K. Droegemeier, and V. Wong, The Advanced Regional Prediction System (ARPS) - A multi-scale nonhydrostatic atmospheric simulation and prthesediction model. Part I: Model dynamics and verification,

Meteorology and Atmospheric Physics, vol. 75, no. 3-4, pp. 161-193, 2000.

14) M. Indeje, F. H. M. Semazzi, and L. J. Ogallo, ENSO signals in East African rainfall seasons, International Journal of Climatology, vol. 20, no. 1, pp. 19-46, 2000.

15) C. Mutai and M. Ward, East African rainfall and the tropical circulation/convection on intraseasonal to interannual timescales, Journal of Climate, pp. 3915-3939, 2000.

16) M. E. Shongwe, G. J. van Oldenborgh, B. van den Hurk, and M. van Aalst, Projected Changes in Mean and Extreme Precipitation in Africa under Global Warming. Part II: East Africa, Journal of Climate, vol. 24, no. 14, pp. 3718-3733, 2011.

17) M. J. McHugh, Impact of South Pacific circulation variability on east African rainfall, International Journal of Climatology, vol. 26, no. 4, pp. 505-521, 2006.

18) C. R. Mirza, T. Koike, Y. Kun, and T. Graf, Retrieval of Integrated Cloud Liquid Water Content and Integrated Water Vapor by Cloud Microphysics Data Assimilation System (CMDAS) Over Ocean by Integrating Satellite Data, AGU Fall Meeting Abstracts, vol. -1, p. 1402, 2006.

19) K. N. Liou, S. C. Ou, Y. Takano, and Q. Liu, A Polarized Delta-Four-Stream Approximation for Infrared and Microwave Radiative Transfer: Part I, Journal of the Atmospheric Sciences, vol. 62, no. 7, pp. 2542-2554, 2005.

20) P. J. Sellers, D. A. Randall, G. J. Collatz, J. A. Berry, C. B. Field, D. A. Dazlich, C. Zhang, G. D. Collelo, and L. Bounoua, A Revised Land Surface Parameterization (SiB2) for Atmospheric GCMS. Part I: Model Formulation, Journal of Climate, vol. 9, no. 4, pp. 676-705, 1996.

(Received September 30, 2012) 